\title{
Author Correction: Boreal forest biomass accumulation is not increased by two decades of soil warming
}

Hyungwoo Lim (D), Ram Oren (D), Torgny Näsholm, Monika Strömgren, Tomas Lundmark, Harald Grip and Sune Linder Correction to: Nature Climate Change https://doi.org/10.1038/s41558-018-0373-9, published online 17 December 2018.

In the version of Letter originally published, there was an error in Fig. 3. Specifically, the $y$-axis label alongside panels $3 a, c$, originally reading "Foliar $[\mathrm{N}]\left(\mathrm{mg} \mathrm{g}^{-1}\right)$ " should instead have read "Foliar [N] (\%)."

Published online: 23 November 2021

https://doi.org/10.1038/s41558-021-01234-Z

(c) The Author(s), under exclusive licence to Springer Nature Limited 2021

\section{Author Correction: Counterbalancing influences of aerosols and greenhouse gases on atmospheric rivers}

Seung H. Baek (D) and Juan M. Lora (D)

Correction to: Nature Climate Change https://doi.org/10.1038/s41588-021-01166-8, published online 4 October 2021.

In the Methods section of the version of this Article originally published, the equations describing the thermodynamic and dynamical contributions were incorrectly transcribed. No results are affected. The changes are described below.

In the second equation following the paragraph starting "For the CESM1 experiments", the equation now reading "Dynamical influence ... initially read "Dynamic influence." In the first equation following the paragraph beginning "By extension:", the final term " $A L L_{q_{1}}$ " initially read " $A L L_{q_{2}}$ " In the third equation following that paragraph, the final term now reading "XAER $R_{1}$ " initially appeared as "XAER $q_{q_{2}}$ " In the fourth equation now reading "Dynamical influence of $\mathrm{XAER}=\mathrm{XAER}_{u_{2}} \mathrm{XAER}_{q_{1}^{*},}, \mathrm{XAER}_{u_{1}} \mathrm{XAER}_{q_{1}}$ " " $\mathrm{XAER}_{q_{1}^{*}}$ " initially appeared as " $\mathrm{ALL}_{q_{1}^{*}}$ ". The fifth equation now ends " $X G H G_{q_{1}}$ " rather than " $X G H G_{q_{2}}$ " In the final equation, now reading "Dynamical Influence of XGHG $=\mathrm{XGHG}_{u_{2}} \mathrm{XGHG}_{q_{1}^{*}},-\mathrm{XGHG}_{u_{1}} \mathrm{XGHG}_{q_{1}}$," "XGHG $\mathrm{q}_{1}^{*}$ " replaces "ALL $\mathrm{q}_{1}^{*}$ ".

The online version of the Article has been corrected.

Published online: 12 November 2021

https://doi.org/10.1038/s41558-021-01235-y

( $)$ The Author(s), under exclusive licence to Springer Nature Limited 2021 